\title{
PEMBINAAN DAN PENGEMBANGAN USAHA KECIL KOPRA BAGI MASYARAKAT RT 003 DAN RT 004 DESA SUNGAI AWAN KANAN KABUPATEN KETAPANG DALAM RANGKA PENINGKATAN EKONOMI KELUARGA
}

Copra Guidance And Small Business Development For RT 003 RT 004 Sungai Awan Kanan Village, District Ketapang In Order To Increasing Economic Family

\author{
Helanianto $^{1)}$, Nely Kurnila ${ }^{2)}$ \\ ${ }^{1)}$ Program Studi Perawatan dan Perbaikan Mesin, Politeknik Negeri Ketapang \\ ${ }^{2}$ Program Studi Teknik Pertambangan, Politeknik Negeri Ketapang \\ email : helanianto@yahoo.com
}

\begin{abstract}
Indonesia as one of the island nation and the agrarian wing is necessary to increase the productivity of copra to support other commodities such as edible oil industry, soap industry as derivative products, and others. Where according to national statistics show an increase in the consumption of related products by $5.5 \%$ per year with production figures at $4.47 \%$ rate per year. The increase in these requirements would need to be coupled to the supporting base processing technology that can support the capacity and life of the product to be stored longer at warehouse. Most of our people are still doing conventional copra drying technique, where natural factors become part of the problem to produce more copra capacity. Besides these negative impacts is the ability of copra in a shorter shelf life due to the level of humidity. The methods used in handling problems faced by local communities is the implementation / transfer (science and technology) form of utilization of drying technology more modern type, where the community is prepared to transfer technology so copra produced is not limited by weather conditions and can produce more leverage. There are five stages to be passed in science and technology transfer activities; socialization program application of science and technology for the community, coaching and business development copra, the application of technology transfer, copra production. Coaching and small business development were highlighted copra has a capacity of 30-50 kg of coconut in a drying time of 5 hours for one production. With the availability of two tools that can increase capacity up to $100 \mathrm{~kg}$ of coconut ready though so that could be achieved a production of 3 tons in a month depending the availability of the results of the community garden.
\end{abstract}

Keywords : training and business development of copra

\begin{abstract}
ABSTRAK
Indonesia sebagai salah satu negara kepulauan dan berhaluan agraris sangat perlu meningkatkan produktifitas kopra untuk menunjang komoditi lainnya seperti industri minyak nabati, industri sabun sebagai produk turunan, dan lain-lain. Dimana menurut data statistik nasional menunjukan adanya peningkatan konsumsi produk terkait sebesar $5.5 \%$ per tahun dengan angka laju produksi sebesar $4.47 \%$ per tahun. Peningkatan kebutuhan tersebut tentu perlu dibarengi juga dengan dukungan teknologi pengolahan dasar yang bisa menunjang kapasitas dan umur produk untuk bisa disimpan lebih lama dipenampungan. Kebanyakan masyarakat kita hingga saat ini masih melakukan teknik pengeringan kopra secara konvensional, dimana faktor alam menjadi bagian masalah untuk menghasilkan kapasitas kopra yang lebih banyak. Selain itu dampak buruknya adalah kemampuan kopra dalam umur simpan menjadi lebih pendek dikarenakan tingkat kelembaban udara. Adapun metode yang diterapkan dalam penanganan masalah yang dihadapi masyarakat setempat adalah dengan penerapan/transfer (Ipteks) berupa pemanfaatan teknologi pengeringan dengan jenis yang lebih
\end{abstract}


modern, dimana masyarakat dipersiapkan untuk alih teknologi agar kopra yang diproduksi tidak terbatas oleh kondisi cuaca dan bisa berproduksi lebih maksimal. Ada empat tahapan yang akan dilalui dalam kegiatan transfer Ipteks; sosialisasi program penerapan ipteks bagi masyarakat, pembinaan dan pengembangan usaha kopra, aplikasi alih teknologi, pembuatan kopra. Pembinaan dan pengembangan usaha kecil kopra yang digerakan ini mempunyai kapasitas 30$50 \mathrm{~kg}$ kelapa dalam waktu pengeringan 5 jam untuk satu kali produksi. Dengan ketersediaan dua buah alat maka bisa meningkatkan kapasitas hingga $100 \mathrm{~kg}$ kelapa siap olah sehingga bisa dicapai produksi sebesar 3 ton dalam satu bulan bergantung ketersediaan hasil kebun masyarakat.

Kata kunci : pembinaan dan pengembangan usaha kopra

\section{PENDAHULUAN}

Kelapa merupakan tanaman budidaya yang tersebar luas didaratan tropis dengan daerah endemis pesisir pulau dan dataran rendah hingga ketinggian $900 \mathrm{~m}$ dari permukaan laut. Indonesia sebagai salah satu negara yang terletak digaris Khatulistiwa dan dikenal sebagai negara kepulauan tentu tidak terlepas dari ragam tanamaan tropis yang salah satunya adalah kelapa tersebut. Kelapa menempati peringkat cukup baik dalam kategori tanaman budidaya. Yang mana data statistik nasional menunjukan adanya peningkatan kebutuhan masyarakat dari tahun ketahun. Pada skala nasional, diperkirakan kebutuhan konsumsi akan produk kelapa meningkat 5.5 $\%$ per tahun dengan laju produksi produk sebesar $4.37 \%$ dalam tiap tahunnya. Dengan skala tersebut berarti ada kebutuhan yang tidak terakomodir sebesar $1.13 \%$ yang secara otomatis menjadi faktor penting dalam peningkatan budidaya perkebunan kelapa dan industri olahannya di Indonesia. Laju pertumbuhan konsumsi tersebut hanya bisa diimbangi dengan upaya peningkatan produksi kelapa melalui pengelolaan budidaya yang baik sehingga bisa menghasilkan 1.5 ton kopra/ha/tahun (Suhardiyono, 1993).

Kebutuhan peningkatan produksi kelapa tersebut menjadi titik tolak pemikiran untuk menunjang skala produksi dengan mekanisasi pembuatan produk kopra secara baik dan efisien.Yang mana daya topang produksi konvensional masih mengalami keterbatasan dengan kurang bersahabatnya alam yang akan mempengaruhi kelembaban produk dan kecepatan produksi. Dan dengan munculnya pengering kopra jenis oven berbagai type diharapkan masyarakat banyak belajar dan paham teknik pengeringan kopra dalam alih teknologi, agar kendala yang dihadapi dapat segera diatasi; perkebunan kelapa semakin giat, produktifitas semaki tinggi, dan perekonomian keluarga semakin meningkat. Untuk itu maka perlu dilakukan pembinaan dan pengembangan usaha kecil kopra bagi masyarakat RT 003 dan RT 004 desa Sungai Awan Kanan kabupaten Ketapang dalam rangka peningkatan ekonomi keluarga.

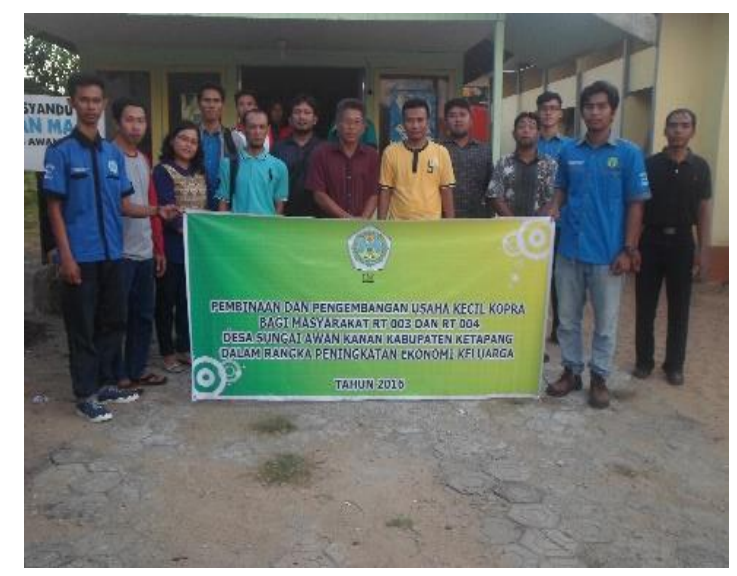

Gbr.1. Pelaksanaan IbM

\section{METODE PENELITIAN}

\section{Alat dan bahan yang digunakan}

Adapun alat yang digunakan untuk menunjang kegiatan ini adalah sebagai berikut: 
1. Oven kopra/2 buah

2. Alat potong/parang

3. Wadah kelapa basah dan kering

4. Timer

5. Timbangan

\section{Rancangan Kegiatan}

Penerapan alih teknologi dalam pembinaan dan pengembangan usaha kecil kopra dimasyarakat RT 003 dan RT 004 desa Sungai Awan Kanan memerlukan saran-prasrana yang patut atau layak menjadi contoh, dimana masyarakat membutuhkan aplikasi secara langsung mengenai teknik dan mekanisme pengeringan yang lebih baik untuk alih teknologi dari pengolahan sekala konvensional yang selama ini mereka jalani. Dalam penerapan teknik pengeringan jenis oven ini dibutuhkan dua alat pengering bahan bakar gas LPG dengan kapasitas kurang lebih $30-50 \mathrm{~kg}$ per alat pengering (dua buah pengering type oven gas).

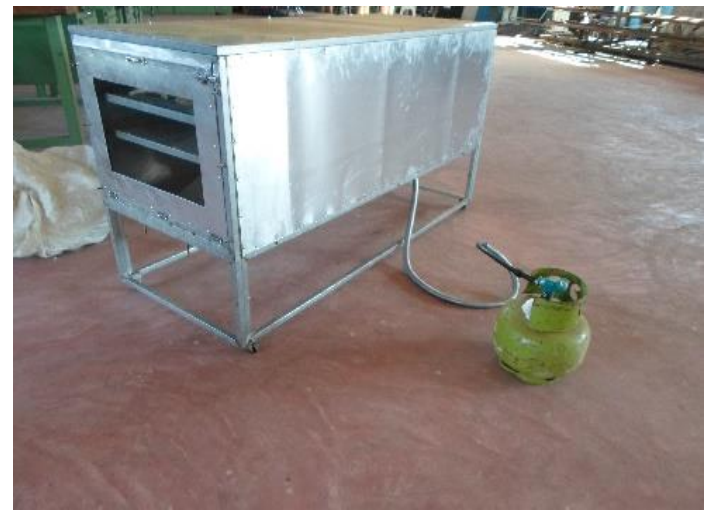

Gbr.2. Oven gas Kopra

Langkah pertama dalam teknik pengeringan kopra jenis ini adalah mempersiapkan kelapa belah tanpa cangkang. Kelapa-kelapa yang sudah siap dimasukan kedalam slot pengering oven dengan posisi telungkup. Pengeringan selanjutnya dilakukan pada posisi sebaliknya sehinggga proses pengeringan berjalan sempurna selama kurang lebih 5 jam pada nyala api sedang atau tidak terlalu besar. Nyala yang terlalu besar menyebabkan ruang terlalu over heating, mempersempit evaporator daging kelapa sehingga sebaliknya penguapan menjadi lambat.

Pengeringan kurun waktu yang ditentukan menjadi patokan untuk pengeringan kopra selanjutnya. Kopra-kopra yang telah kering diangkat dan dianginkan. Untuk memberikan hasil maksimal, kopra proses ini bisa dijaga dengan penjemuran untuk memperpanjang masa tunggu, mengingat teknik oven lebih berfungsi pada kecepatan proses pengeringan sehingga produksi bisa dilipatgandakan pada masa cuaca kurang bersahabat.

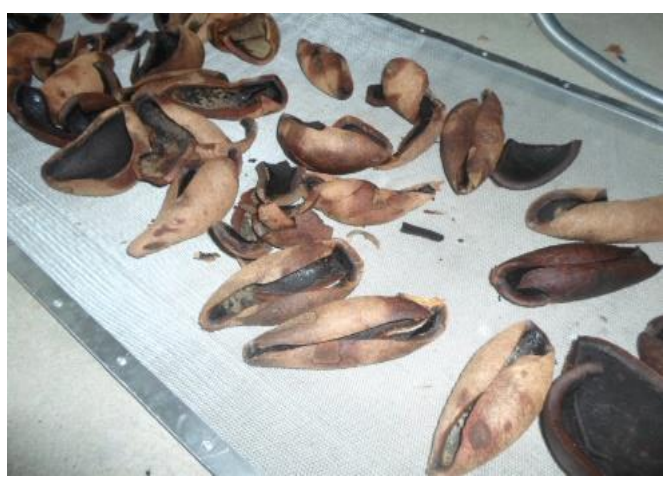

Gbr.3. Kopra hasil pengeringan oven

\section{Metode Pelaksanaan}

Kegiatan ini dilaksanakan di kantor posyandu setempat, yang telah disediakan oleh desa dengan tahapan sebagai berikut;

a. Sosialisasi Program penerapan ipteks bagi masyarakat,

Sosialisasi dilakukan dilingkungan RT 003 - RT 004 desa Sungai Awan Kanan kabupaten Ketapang bertempat dikantor desa. Untuk memberikan pemahaman dan assesment yang bermanfaat bagi pihak terkait, agar tujuan pelatihan program yang dimaksud dapat tercapai dan terlaksana.

b. Pembinaan dan pengembangan Usaha kopra,

Sosialisasi usaha dan pengembangan melalui materi teknik pengeringan kopra, distribusi hasil dan pengelolaan income sebagai langkah pengembangan usaha (oleh tim dan Narasumber).

c. Aplikasi alih teknologi, 
Mesin pengering efisien kopra (type oven) yang diperbantukan, uji coba lapangan, latihan pembuatan kopra bersama masyarakat setempat.

d. Usaha pembuatan kopra,

Setelah pengetahuan teknik pembuatan kopra dengan mekanisme yang baru masyarakat melaksanakan pembuatan kopra terbatas.

\section{HASIL DAN PEMBAHASAN}

Penerapan teknik pengeringan kopra jenis yang digunakan telah dicoba pada Penelitian terdahulu tentang pengeringan kopra dengan jenis mesin pengering tray dryer, Sir Anderson (Jurnal Teknik Mesin, Vol. 3 No.1 Juni 2006) menyebutkan beberapa hasil penelitian terkait pengeringan kopra dengan kandungan air awal 53,18\% pada kinerja mesin pengering rata-rata $65^{\circ} \mathrm{C}$. Hasil menunjukan penurunan kadar air menjadi $6,84 \%$ yang dilakukan proses selama 14 jam untuk 1,06 kg kelapa/jam. Dengan hasil tersebut diperoleh efisiensi pemanasan $22,41 \%$, efisiensi penguapan $86,28 \%$ dan efisiensi pengeringan 19,33\%. Dari hasil tersebut diperoleh kopra dengan kadar air 6-7\%.

Pada program pembinaan usaha kecil kopra ini hasil yang didapat tidak terlalu jauh berbeda, kopra yang dihasilkan cukup kering dengan warna tidak terlalu gelap dan baunya wangi kelapa. Untuk menjaga dari tingkat kelembaban, maka dilaksanakan penjemuran dibawah sinar matahari.

Mengingat kontinuitas produksi kopra masyarakat mengalami penurunan sebagai dampak ketersediaan penampung, maka produksi kopra lokal tidak terlalu maksimal. Hal ini dikarenakan maraknya penggunaa perluasan pertanian yang diterapkan pemerintah kepada masyarakat sehingga luas area perkebunan kelapa semakin berkurang.

Dengan kondisi saat ini, produktifitas pembuatan kopra hanya kurang lebih $20 \%$ yang sebelumnya lebih dari $50 \%$ masyarakat mengolah kelapa sebagai kopra. Dengan adanya alih teknologi yang ditransfer kepada masyarakat, bisa dihasilkan kopra pada kapasits 30-50 kg kelapa siap olah. Maka dengan ketersediaan alat pengering yang digunakan bisa dihasilkan hingga 100 $\mathrm{kg}$ dalam satu sesi pengeringan. Dengan demikian dalam satu bulan bisa dihasilkan kurang lebih 3 ton kelapa siap olah untuk dijadikan kopra. Dengan penerapan mekanisme ini kemampuan produksi jauh lebih baik, hanya saja bergantung dari kesiapan masyarakat untuk pengembangan lebih jauh.

\section{KESIMPULAN DAN SARAN}

\section{Kesimpulan}

Pembinaan dan pengembangan usaha kopra bagi masyarakat dalam rangka peningkatan ekonomi keluarga memberikan kesimpulan sebagai berikut ;

1. Masyarakat masih ketergantungan pada sumber pengeringan konvensional, pengasapan dan penjemuran.

2. Masyarakat belum siap sepenuhnya mengingat ketersediaan alat penunjang jenis oven masih cukup langka.

3. Pembinaan dan pengembangan usaha kecil kopra dengan aplikasi alat jenis oven mempunyai kapasitas 30-50 kg kelapa siap olah per proses dalam kurun waktu 5 jam.

4. Secara kontinyu bisa dihasilkan kurang lebih kapasitas 3 ton kelapa siap olah perbulan, bergantung ketersediaan kelapa hasil perkebunan.

\section{Saran}

Perlu dilakukan pendampingan berkelanjutan agar usaha yang dilakukan masyarakat tumbuh dan berkembang dengan baik. 


\section{DAFTAR PUSTAKA}

Asidu, J J. (1987). Processing Tropical Crops. A Technological Aprroach

Cooke F C. (1951). Copra Manufactur (part). The Malayan Agricultural Journal XXIV

Hall C W. (1957). Drying Farm Corp. Agricultural Process Engineering. John Willey and Sons Inc. New York USA
Hamdan, (1992). Mesin-mesin Processing Decicated Coconut. Unand Padang

J J. (1987). Processing Tropical Crops. A Technological Aprroach

Meyer L H. (1960). Food Chemistry. Reinhold. New York

Palungkun R. (1993). Aneka Produk Olahan Kelapa. Penerbit Swadaya. Jakarta 